\title{
Optimization of adaptive neuro fuzzy inference system based urban growth model
}

\author{
Sassan Mohammady
}

\begin{abstract}
Background: Global urban population has increased from $22.9 \%$ in 1985 to $47 \%$ in 2010. In Iran, population living in urban areas has consistently increased from about $31 \%$ in 1956 to $68.4 \%$ in 2006 . Urban growth as one of the results of rapid population growth, results lots of problems. Thus, monitoring and modelling of the urban expansion is necessary.

Methods: In this research, a novel Adaptive Neuro Fuzzy Inference System (ANFIS)-based methodology has been developed for urban growth modeling, as well as interpreting the relationship between the drivers of urbanization. Then, ANFIS results were compared with those achieved by both ANN and Logistic Regression (LR)-based methodologies using Percent Area Match quantity and Percent Area Match location to assess model goodness of fit.

Results: The proposed ANFIS model which takes the advantages of using neural networks and fuzzy logic at the same time, had the best performances among the three implemented models. It was able to identify important factors in the development and their relationship and influence on the growth of the city.

Conclusions: The research aim is to find a computational based method which can effectively capture, analyse and model the complex nature of spatial phenomenon like urban growth. The proposed ANFIS method due to its structure is able to deals with nonlinear phenomenon. Integration of Remote sensing data, GIS tools and also, computational based method provide us an effective, reliable and also, scientific methods for monitoring, analysing and modeling of environmental phenomenon.
\end{abstract}

Keywords: Urban growth, Modeling, ANFIS

\section{Background}

Unprecedented population growth in the cities has caused a number of problems such as improper planning of infrastructure and urban services, environmental pollution and human health problems. Urban growth as one of its results has created many environmental and socioeconomic problems during the last decades (Triantakonstantis 2012). In fact, urban growth can be considered as the transformation of the rural areas to cities and towns, which is coming along with costs (Deep and Saklani 2014). Urban growth as a complex system is affected by human and non-human based parameters. Spatiotemporal dynamics and incorporation of human drivers

*Correspondence: Sassanmohammady@yahoo.com School of Surveying and Geospatial Engineering, College of Engineering, University of Tehran, Tehran, Iran of land use changes have the most important impact on land use change (Veldkamp and Lambin 2001). Recognition of effective natural, social and spatiotemporal processes that affect urban growth can enhance the accuracy and reliability of the proposed modeling procedure (Foroutan et al. 2012).

Nowadays, due to the high value of land and natural resources and land use change affecting ecosystems and humans, land use change modeling is very important for the concerned urban executives, professionals and researchers. The aim of using urban growth model is to achieve two goals. First, implementation of techniques to understand the spatial relationship between urban growth driving factors (or proxies for them) and historical changes in urban land use. Second, projection of spatial changes in land use based on scenarios of changes in its drivers (Meiyappan et al. 2014). With analyzing 
historical spatiotemporal information, nature of spatiotemporal dynamics of land use changes resulted from different land use policies can be understood which can serve as a basis for developing possible growth scenarios essential for sustainable urban planning and development (Tayyebi et al. 2011).

Recently, a large number of urban expansion models have been implemented in so many researches. Among these models, artificial neural networks (ANN) and logistic regression (LR) have been so popular (Triantakonstantis and Mountrakis 2012). Logistic regression due to its simple and interpretable structure have been used in this field. On the other hand, ANN due to its fast and parallel processing and also, learning ability for obtaining the expansion patterns, have been used. These popular methods have some disadvantages, too. LR due to its linear structure is unable to deal with the nonlinear parts of the spatial phenomenon. On the other hand, lack of flexibility is one of the ANN disadvantages. Also, ANNs are unable to deal with qualitative uncertainty, too. In this condition, combinations of ANN and Fuzzy Inference Systems (FIS) obviate many of their shortcoming. In other words, by integrating ANNs and fuzzy systems, the capabilities of ANNs self-learning with the linguistic expression function of fuzzy inference can be fused (Pahlavani and Delavar 2014). Dickerson and Kosko (1996), Mitaim and Kosko (2011), Huang and Xing (2002), and Yan (2010) have had such studies that confirm the possibility of extracting fuzzy-rules from training data by integrating fuzzy systems with ANNs. Thus, ANFIS as an ANN based method which takes benefit of fuzzy inference system seems to be appropriate in spatial phenomenon like urban expansion.

\section{Future studies perspective}

Asselt et al. (2010), define three different categories of futures studies and how they handle uncertainty, although, different labels are used to categorise futures studies in (Armstrong and Fildes 2006; IPTS-JRC, 2008). Following Asselt et al. (2010), the three proposed categories of future studies include: forecasting, foresight and normative future studies. Forecasting, shows one relatively certain image of the future. The future can be seen as the logical result of the past (Veenman 2013). In fact, Forecasting is a short-, medium- or long-term estimation of future in a specific research area by means of scientific methodology (Cuhls 2003). For this approach, past-based scientific knowledge and models based on these assumptions are considered a reliable basis for making statements about the future (Veenman 2013). In the other words, Forecasting extends past and present patterns and trends into the future, implying a smooth transition between the past, present and the future (Nowotny 2008). Foresight is the second of
Asselt's categories for futures studies that more strongly emphasizes cognitive uncertainty is foresight which deals with multiple possible and plausible future (Veenman 2013). Foresight draws conclusions for the present and is therefore a broad range policy instrument that can serve various objectives (Cuhls 2000). In fact, Foresight is presented in a scenario study as a rich detailed portrait of a plausible future world, or as future states of a system (Berrogi 1997). A scenario is not a forecast but a plausible description of what might occur (Enserink et al. 2010). In foresight studies, future images are given with two or more scenarios (Schwartz 1991; Goodwin and Wright 2010). It is uncertain which trends develop, continue or stop, and which unexpected events might happen, since multiple, alternative futures are possible in foresight analysis (Veenman 2013). Normative, is the third category of future studies of Asselt et al. (2010). In contrast to forecasting and foresight studies, normative futures studies favor normativeness instead of trying to be 'neutral' (Veenman 2013). The normative studies include two branches: backcasting and critical futures studies. Backcasting is concerned with how desirable futures can be created, rather than what futures are likely to occur. In backcasting, one envisions a desired future endpoint, and then works backward to determine what policy measures would be required to achieve such a future. Critical future studies emphasizes that images of possible futures are not neutral but represent particular desires, values, cultural assumptions and world views (Asselt et al. 2010). Such future studies sketch a future that is considered ideal, for example, a situation of peace and tolerance, or a situation where the environmental burden is minimised. These types of future studies do not attempt to imagine one or more possible images of the future or one or more possible images of development without a statement being made about the desirability of it. According to Asselt's category, this paper implemented the first category, forecasting.

\section{Cognition based perspective}

Several theoretical perspectives or frameworks have been developed in the study of cognition to organize research, and provide competing and cooperating explanations for cognitive phenomena (Montello and Freundschuh 2005). There are seven major perspectives which provide ample theoretical and conceptual raw material for interpreting past research on cognitive issues in geographic information science, and also, for providing directions for future research (Montello and Freundschuh 2005). They include: constructivism perspective, ecological perspective, information-processing perspective, connectionist perspective, linguistic perspective, situated cognition perspective and evolutionary perspective (Montello and Freundschuh 2005). 
In this paper, the research methodology use the information-processing perspective and connectionist perspective categories. Information-processing perspective emphasis on the roles of strategies and metacognition (cognition about cognition) that control the use of cognitive structures when reasoning about particular problems (Montello and Freundschuh 2005). An example is a person using a particular set of rules to perform a GIS procedure on several data layers. The information-processing approach is inspired by traditional rule-based digital computing and is represented by work in formal/ computational modeling and symbolic AI. In this study, the data processing section utilized this cognition. For example, Landsat imageries classification in this paper which done using ENVI Software is inspired by information-processing cognition.

Also, this paper in the modeling section (ANFIS and ANN models) utilized the Connectionist perspective cognition. Connectionist perspective cognition suggests that, cognition operates by the activation of complexly interconnected networks of simple neuron-like nodes. The output of a network is determined by the patterns of interconnecting links, and weights on these links, that affect output from one node to another (Rumelhart and McClelland 1986). It is claimed to be a model of cognition that explicitly ties mental activity to the operation of the brain and nervous system, or at least a neurologically plausible model of the nervous system (Montello and
Freundschuh 2005). Thus, urban growth as a complex system needs different cognition perspectives to be considered in order to model the nature of urban expansion in a better and more accurate way.

In this paper, an ANFIS structure has been proposed for modeling urban land use change and compared its performance with the two popular land use change models, ANN and LR. This paper includes these steps (Fig. 1). The employed dataset including Landsat imageries, road networks and Digital Elevation Model (DEM). Next, we generated training data ("Creating the training data for the LR, ANN and ANFIS models" section) to train the ANFIS, ANN and LR models (Figs. 7, 8; Table 5). The first evaluation step was implemented using comparison between the real training data and the simulated ones using PAM location and quantity (Table 6). Then, the best model was selected and the 2000 and 2006 maps (Figs. 10, 11) simulated and Percent Area Match location and quantity have been used for evaluating the goodness of fit the simulated maps (Tables 7, 8).

\section{Methods}

In this section, after introducing the study area ("Study area" section), data pre-processing step ("Data pre-processing" section) and proposed methods ("Artificial neural network specification", "ANFIS specification", "LR" sections), the training data are generated ("Creating the training data for the LR, ANN and ANFIS models"

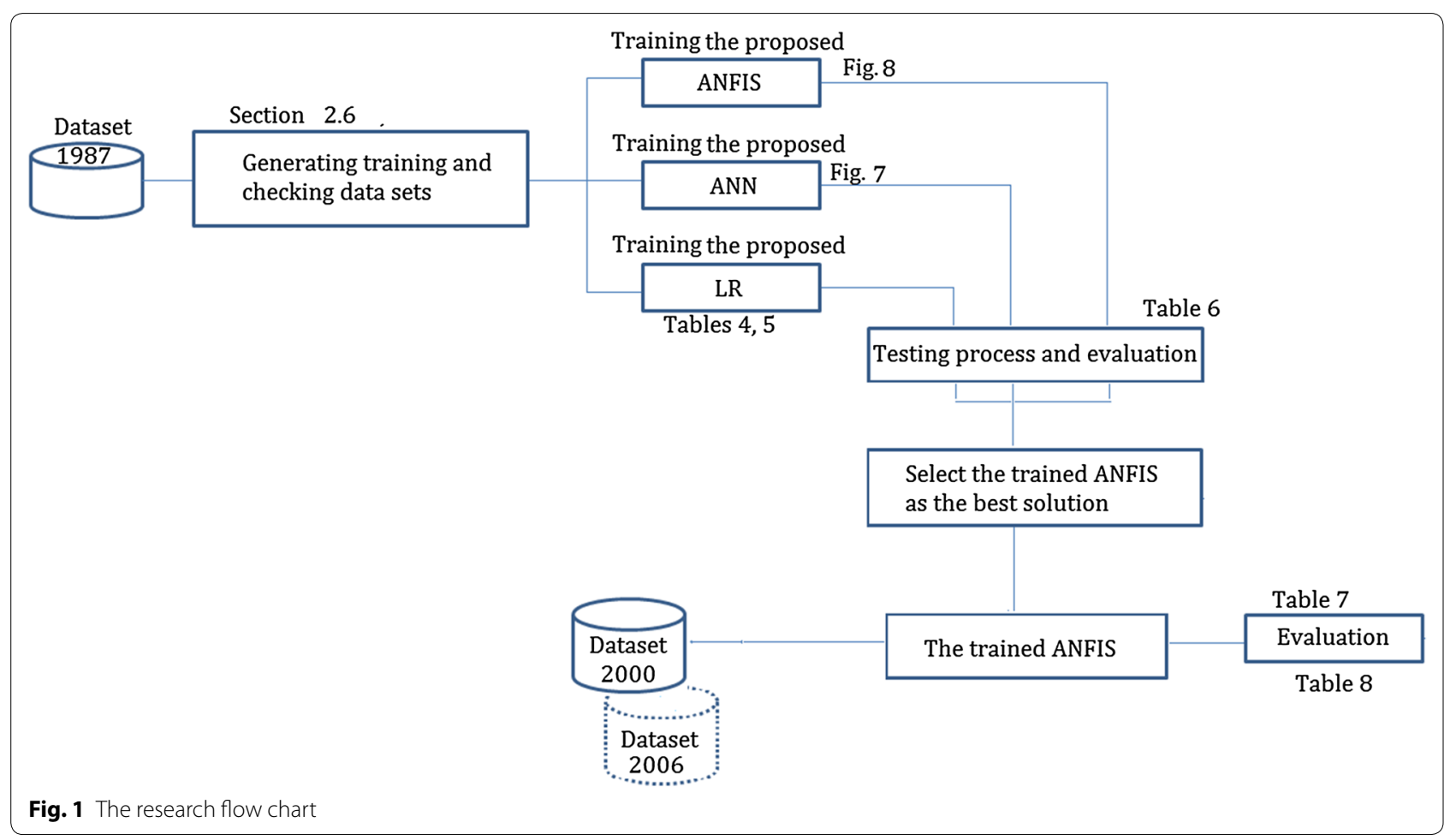



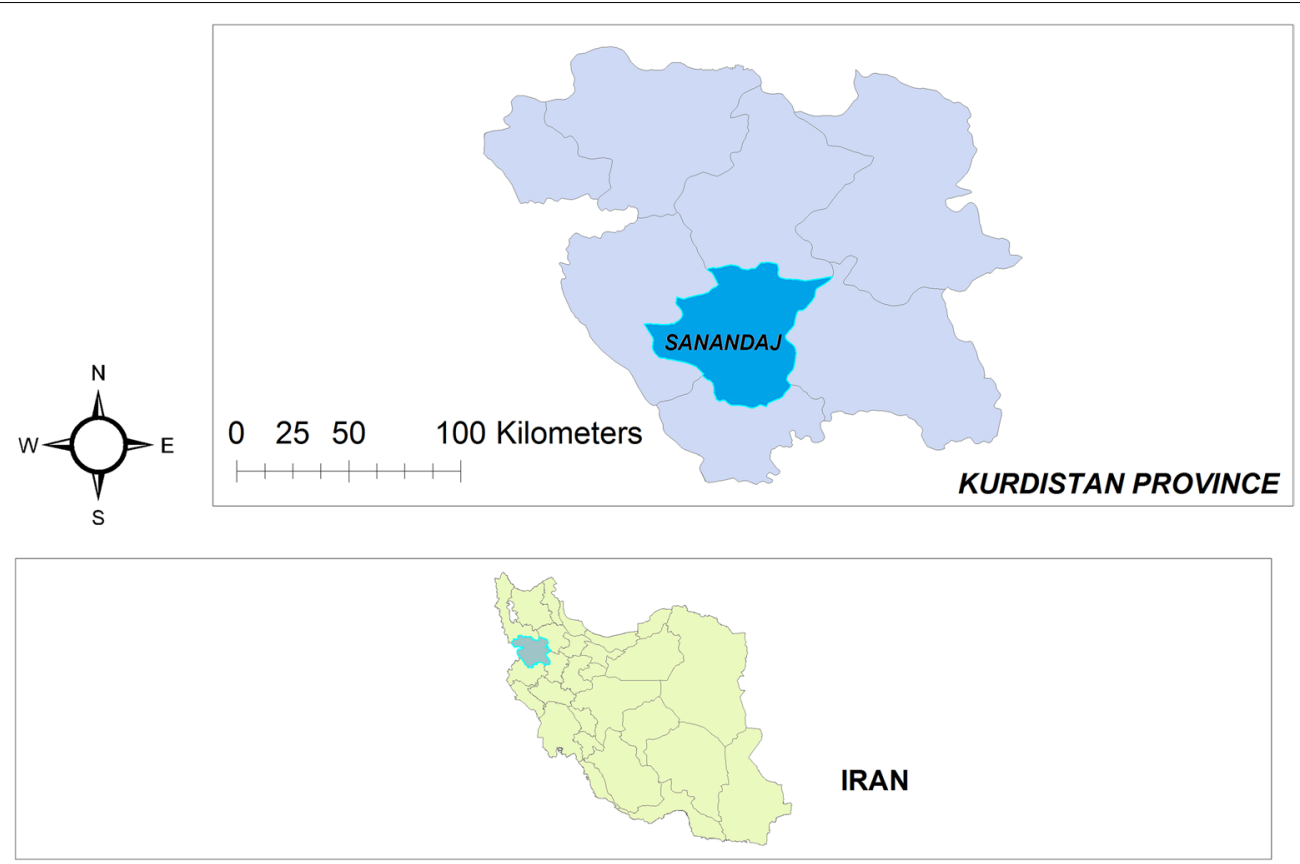

Fig. 2 The study area

section). Then, the three proposed models trained using the training data and PAM quantity and location as the accuracy assessments have been used to determine the best solution between the three proposed models. Then by using the best learned model, we simulated the 2000 and 2006 maps and evaluated the results using the same accuracy assessment factors. Figure 1 presents the flow chart describing the main steps in urban growth modeling.

\section{Study area}

The study area in this research is the city of Sanandaj in Iran that covers around 3688.6 (ha) with geographical coordinates $35^{\circ} 18^{\prime} 40^{\prime \prime} \mathrm{N}$ and $46^{\circ} 59^{\prime} 40^{\prime \prime} \mathrm{E}$ (Fig. 2). This city has had a large urban population growth in the last few decades. In overall, socioeconomic processes such as migration, urban sprawl and agricultural developments often contribute to the urbanization. In this city, population growth, migration from neighbourhood cities and even adjacent province to this city are the most important reasons of expanding the city within the last few decades. Figure 3 shows urban population growth in the last decades in this city (Statistical Center of Iran).

\section{Data pre-processing}

Nowadays, a plethora of researches in urban management are focused on using GIS, remote sensing and photogrammetric data for simulation modeling of urban growth (Dadras et al. 2015). GIS can be considered as a spatial data management tool which has been used in data pre-process, process and post-process stages. It can be considered as a pre-processor by generating input data derived from a variety of sources; also at each stage of analysis as a data management tool; and finally as a postprocessor for data visualization and planning (Kumar et al. 2013). In this condition, remote sensing imageries are a reliable and accurate data sources which are valuable for the analysis and modeling of urban status (Jensen and Cowen 1999; Batty and Howes 2001; Donnay et al. 2001; Herold et al. 2001; Clarke et al. 2002). Temporal frequency, availability of free to less expensive data sources of satellite imagery and image processing techniques have greatly enhanced the potential for monitoring and mapping urban growth and monitoring urban land use change (Goodchild 2000; Im et al. 2008), urban land use dynamics (Herold et al. 2003), landscape pattern analysis (Li and Yeh 2004), and urbanization (Weng 2007). Remote sensing data used in this research, comes from three satellite imageries in 1987, 2000 and 2006 from Landsat TM and $\mathrm{ETM}^{+}$(Fig. 4) with pixel sizes of 28.5 and $30 \mathrm{~m}$, respectively in UTM-WGS 1984 Zone $38 \mathrm{~N}$. The satellite imageries were chosen due to their proper spatial and temporal resolutions presenting different land use policies in Iran in different decades. For the imageries classification, Anderson level 1 due to nature of urban growth (changing from non urban to urban) is considered as the classification scheme and the imageries are classified in four categories including vegetation, developed 


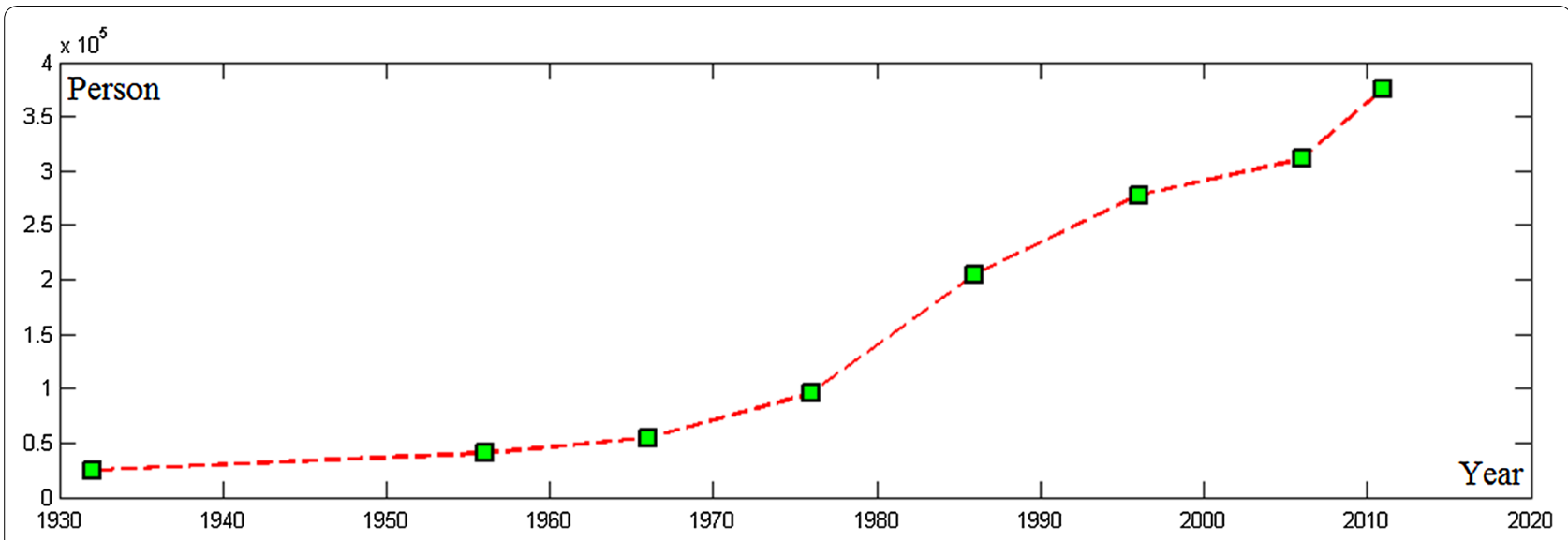

Fig. 3 Urban population growth in the last decades in Sanandaj (Statistical Center of Iran)
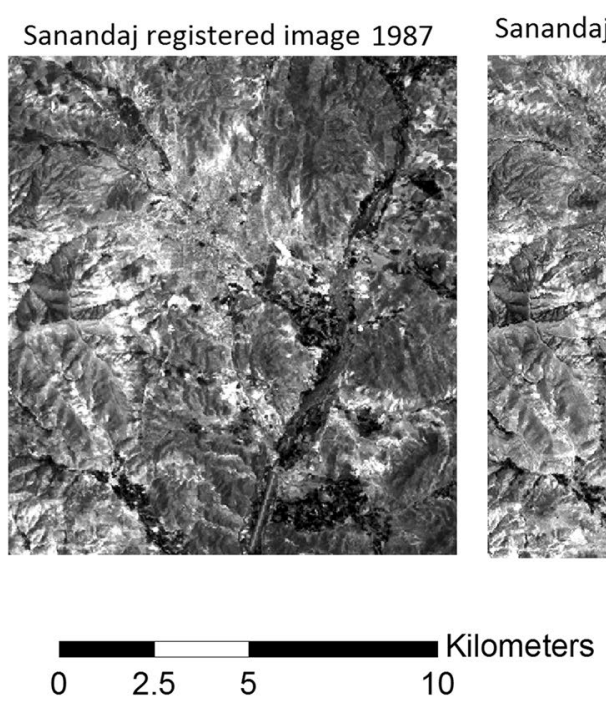

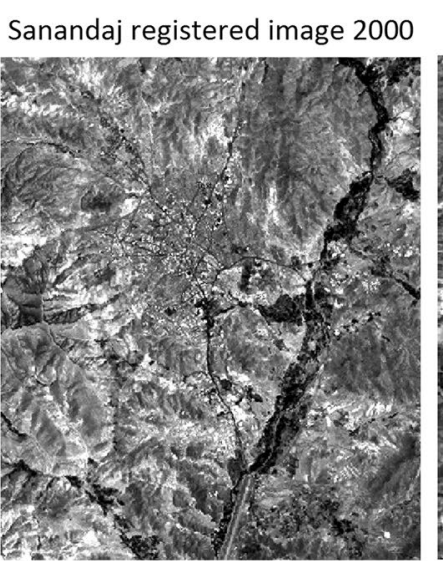

Datum: WGS-1984

Projection System:UTM Zone 38N
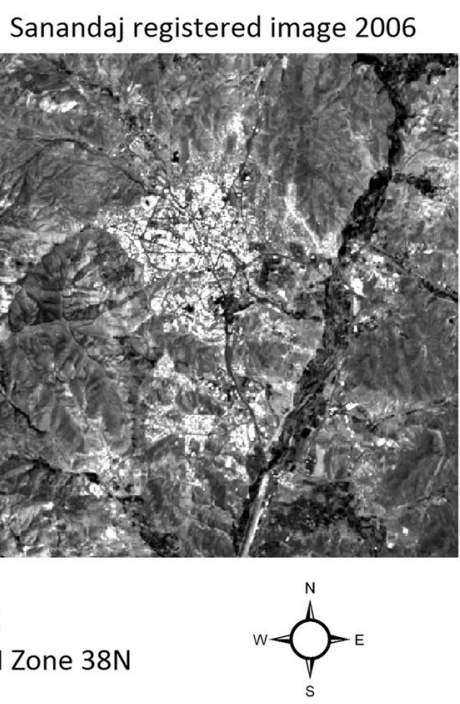

Fig. 4 Sanandaj registered satellite imageries

area, highland area and water body (Fig. 5). Maximum likelihood classification method has been used for land use/cover classification. Kappa coefficient obtained from the classification, ranges from 89.17 to $92.68 \%$. According to Pijanowski et al. (2005) and Sousa et al. (2002), all of the obtained Kappa statistics values are considered excellent. Whereas overall accuracy have been obtained equal to $94.27 \%$ for $1987,92.57 \%$ for $2000,94.71 \%$ for 2006, respectively. According to Anderson et al. (1976), the obtained overall accuracies are acceptable. Tables 1, 2 and 3 present user and producer's accuracy for 1987, 2000 and 2006 imageries.

The main road map, green spaces and faults are also prepared in GIS environment. Risk assessment factor is an unavoidable factor in urban management. Thus, considering this factor in the modelling of the city is reasonable. In this research, faults are considered as the area which has the potential of danger. Thus, distance to this dangerous area is another factor which has been considered in the dataset. The developed area and city center layers are obtained from the classified images. The distances to the developed area, green spaces, roads, city center, faults and also, number of urban cells in a 3 by 3 kernel are obtained in Matlab. The slope and elevation layers are from AsterDEM data. The final dataset includes distance to main road, distance to green spaces, distance to faults, distance to developed area, slope, elevation, distance to district centers and number of developed cell in a 3 by 3 neighbourhood (Fig. 6). 

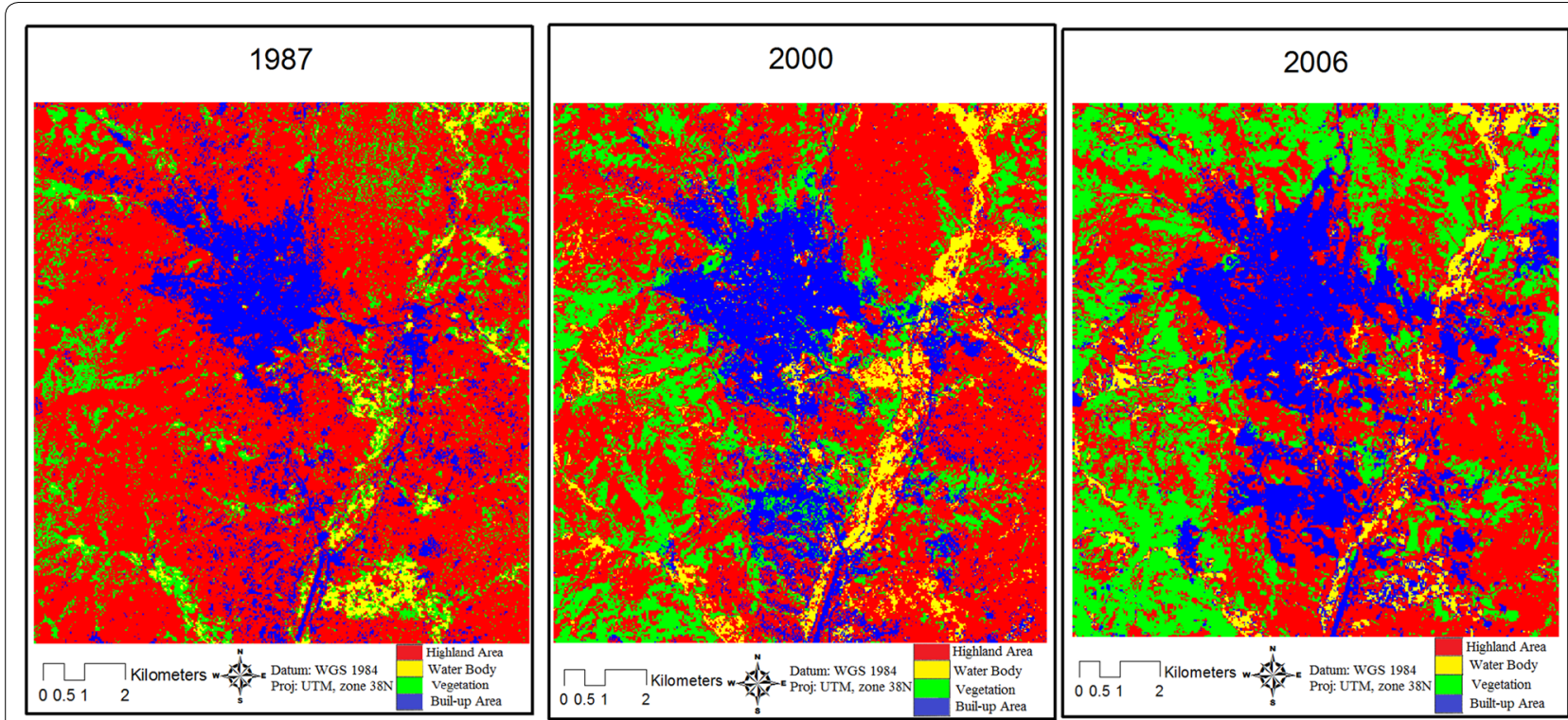

Fig. 5 Sanandaj classified imageries

Table 1 Classification accuracy (1987)

\begin{tabular}{lccccc}
\hline Class name & $\begin{array}{l}\text { Reference } \\
\text { totals }\end{array}$ & $\begin{array}{l}\text { Classified } \\
\text { totals }\end{array}$ & $\begin{array}{l}\text { Number } \\
\text { correct }\end{array}$ & $\begin{array}{l}\text { Producer's } \\
\text { accuracy }\end{array}$ & $\begin{array}{l}\text { User's } \\
\text { accuracy }\end{array}$ \\
\hline Water body & 27 & 28 & 26 & 96.30 & 92.86 \\
Built-up area & 38 & 49 & 38 & 100 & 77.55 \\
Highland area & 155 & 149 & 144 & 92.90 & 96.64 \\
Vegetation & 89 & 83 & 83 & 93.26 & 100.00 \\
Total & 309 & 309 & 291 & & \\
\hline
\end{tabular}

Table 2 Classification accuracy (2000)

\begin{tabular}{lccccc}
\hline Class name & $\begin{array}{l}\text { Reference } \\
\text { totals }\end{array}$ & $\begin{array}{l}\text { Classified } \\
\text { totals }\end{array}$ & $\begin{array}{l}\text { Number } \\
\text { correct }\end{array}$ & $\begin{array}{l}\text { Producer's } \\
\text { accuracy }\end{array}$ \\
\hline Water body & 123 & 120 & 120 & 97.56 & $\begin{array}{l}\text { User's } \\
\text { accuracy }\end{array}$ \\
Built-up area & 177 & 219 & 173 & 97.74 & 79 \\
Highland area & 505 & 483 & 455 & 90.10 & 900 \\
Vegetation & 286 & 269 & 262 & 91.61 & 97.40 \\
Total & 1091 & 1091 & 1010 & & \\
\hline
\end{tabular}

Table 3 Classification accuracy (2006)

\begin{tabular}{llllll}
\hline Class name & $\begin{array}{l}\text { Reference } \\
\text { totals }\end{array}$ & $\begin{array}{l}\text { Classified } \\
\text { totals }\end{array}$ & $\begin{array}{l}\text { Number } \\
\text { correct }\end{array}$ & $\begin{array}{l}\text { Producer's } \\
\text { accuracy }\end{array}$ & $\begin{array}{l}\text { User's } \\
\text { accuracy }\end{array}$ \\
\hline Water body & 118 & 147 & 117 & 99.15 & 79.59 \\
Built-up area & 176 & 177 & 175 & 99.43 & 98.87 \\
Highland area & 243 & 214 & 213 & 87.65 & 99.53 \\
Vegetation & 87 & 86 & 86 & 98.85 & 100 \\
Total & 624 & 624 & 591 & & \\
\hline
\end{tabular}




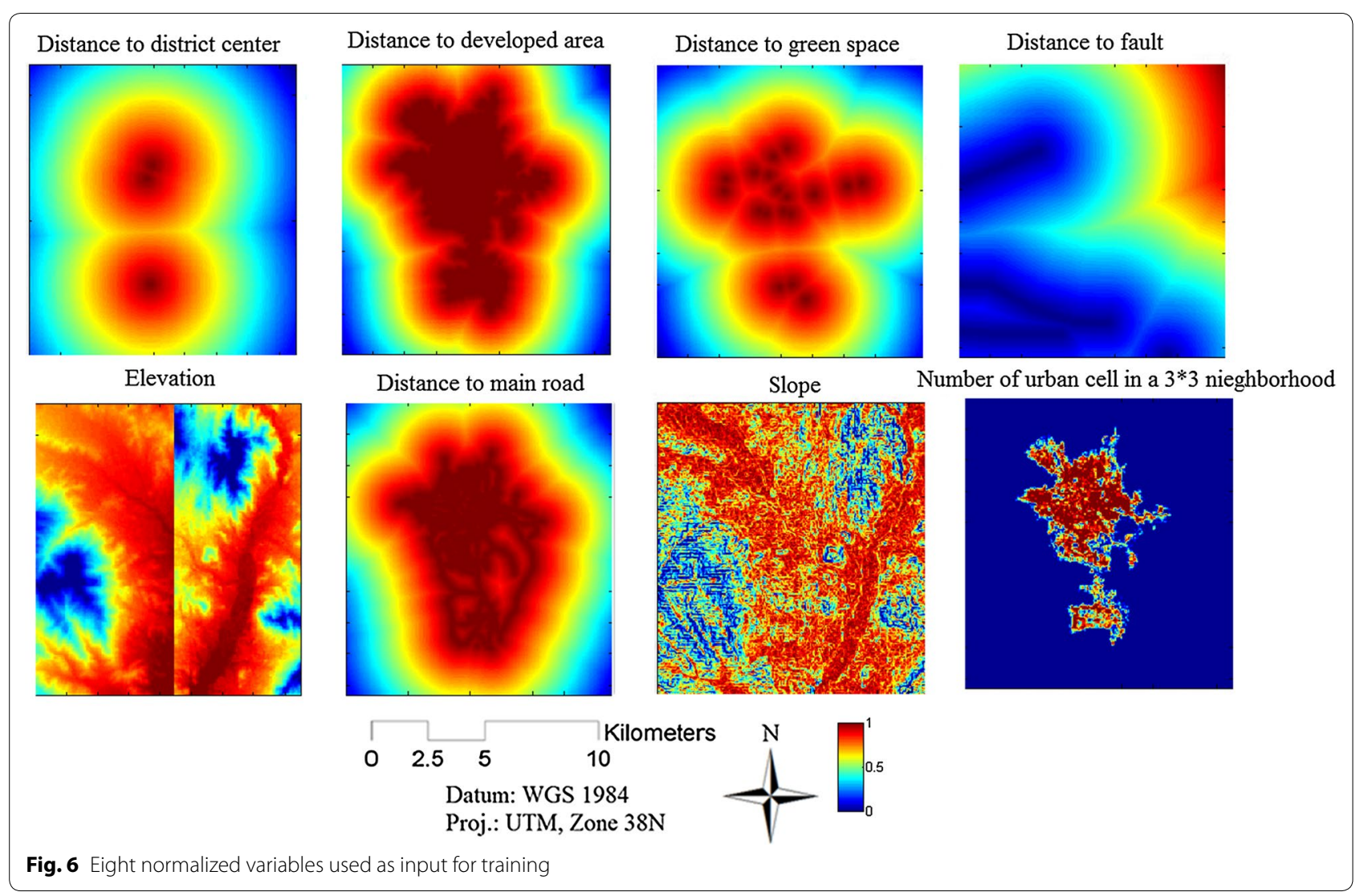

\section{Artificial neural network specification}

According to the recent researches, data driven inductive methods are popular. Because first, they have been extracted from the data and relation between them. Second, they tend to perform better in reproducing existing spatial patterns (Overmars et al. 2007; Koomen et al. 2015). Artificial neural networks with capacity of nonlinear, parallel and highly complex processing have been employed in many fields such as climate forecasting (Panagoulia 2006), agricultural land suitability assessment (Wang 1994), remote sensing (Morris et al. 2005) and land use change and urban growth modeling (Tayyebi et al. 2011; Pijanowski et al. 2002, 2009, 2014). Artificial neural network is a powerful tool in environmental modeling (Li and Yeh 2001). The ability to learn is the most important feature of this method. In the other words, the network uses data to identify patterns and relationships among the data. According to Almeida et al. (2008), Li and Yeh (2002), ANN method has the ability to capture the non-linear relationships presented in many geographic phenomena (Li and Yeh 2002; Li et al. 2003). Thus, it can be used due to this ability to compute the conversion probabilities for competing multiple land uses. There is a general consensus among researchers in the field of urban modeling that empiricism is a reasonable way to determine the most optimum and the best structure in neural net for a specific problem (Li and Yeh 2001; Yeh and Li 2003; Guan and Wang 2005; Almeida et al. 2008). Also, there is no certain rule for determining optimum number of hidden layer and also neurons in the hidden and output layers. In this study, an ANN structure with three layers has been used. The input layer includes eight neurons. Also, The output layer includes two neurons which is the number of classes (urban and non-urban). Tangent sigmoid in the hidden layer and (Purelin) linear function as the transfer function in the output layer have been used.

\section{ANFIS specification}

ANFIS was introduced first by Jang (1993). This method is developed through the integration of ANN and fuzzy logic models which enables us to integrate learning capability and human knowledge together in one method and at the same time to cover many of their shortcomings such as lack of flexibility in ANN and finding out the correct positions and shapes for membership functions in FIS (Mohammady et al. 2013). In this algorithm, during the learning process, membership functions in fuzzy structures change toward their optimal values (Mohammady et al. 2013). In this paper, an ANFIS structure 
which generated a Sugeno-type Fuzzy Inference System (FIS) structure using subtractive clustering method has been used. The subtractive clustering method has been chosen as the generating FIS method, because of high dimension of the input data. The rule extraction method first uses the subtractive clustering function to determine the number of rules and antecedent membership function and then, uses linear least squares estimation to determine each rules consequent equation (Chiu 1994). Gaussian membership function as the input membership function has been used. Since the dataset has 8 input variables and 1 output variable, sub cluster constructs a FIS with 8 inputs and 1 output. In this method, sub clustering identifies the number of membership function for each input and output which is as many as the number of clusters (Chiu 1994).

LR

Logistic regression method was proposed by Christensen (1997). This method is one of the most popular methods for urban growth modeling (Triantakonstantis and Mountrakis 2012). Linear regression explores the relationships between independent variables and urban land uses. In this field, the dichotomous dependent variable is urban change, where a value of 1 indicates change from nonurban to urban and 0 indicates no change. According to Christensen (1997), the probability of each ground pixel to being developed to an urban land is considered by [Eq. (1)]

$$
P=\frac{\exp \left(B_{0}+\sum_{i=1}^{n} B_{i} X_{i}\right)}{1+\exp \left(B_{0}+\sum_{i=1}^{n} B_{i} X_{i}\right)}
$$

where, $P$ is the probability of land use change for each cell, $X_{i}$ is the effective parameters in urban growth, $B_{0}$ is the constant parameter, $B_{i}$ is the coefficients of each of the independent parameters that must be calculated. $P$ indicates the probability of change from non-urban to urban. The output of the $P$ is always a value between 0 and 1 .

\section{Creating the training data for the LR, ANN and ANFIS models}

The selection of training dataset size for ANNs should be done carefully, because ANNs have the tendency to overfit data (Huang and Huang 1991). According to the proposed activation functions in each method, all of the input values converted to -1.0 to 1.0 range for the ANN model and between 0 and 1 for ANFIS and LR. Normalization function which is used for projecting the data between 0 and 1 (ANFIS and LR) is shown in [Eq. (2)] and [Eq. (3)] for ANN structure.

$$
x_{j}^{\prime}=\frac{x_{j}-\min \left(x_{j}\right)}{\max \left(x_{j}\right)-\min \left(x_{j}\right)}
$$

$$
\begin{aligned}
& x_{j}^{\prime}=2 *\left(\frac{x_{j}-\min \left(x_{j}\right)}{\max \left(x_{j}\right)-\min \left(x_{j}\right)}-0.5\right) \\
& \left(x_{1}, x_{2}, \ldots x_{n}\right), \quad n \in(1,2,3, \ldots, 8) \\
& \left(x_{1}^{\prime}, x_{2}^{\prime}, \ldots, x_{n}^{\prime}\right), \quad n \in(1,2,3, \ldots, 8),
\end{aligned}
$$

where, $x_{j}$ : real value for each input data and $x_{1}^{\prime}$ : normalized value for each input data.

The final matrix which is prepared to enter ANFIS structure is shown as follows:

$$
\text { Data }=\left(\begin{array}{cccccc}
x_{11}^{\prime} & x_{12}^{\prime} & x_{13}^{\prime} & \cdots & x_{18}^{\prime} & 1 \\
& \vdots & & \ddots & & \vdots \\
x_{n 1}^{\prime} & x_{n 2}^{\prime} & x_{n 3}^{\prime} & \cdots & x_{n 8}^{\prime} & 1 \\
x_{n+11}^{\prime} & x_{n+12}^{\prime} & x_{n+13}^{\prime} & \cdots & x_{n+18}^{\prime} & 0 \\
& \vdots & & \ddots & & \vdots \\
x_{n+m 1}^{\prime} & x_{n+m 2}^{\prime} & x_{n+m 3}^{\prime} & \cdots & x_{n+11}^{\prime} & 0
\end{array}\right)
$$

$i=1,2,3, \ldots, n, n+1, n+2, n+m$ and $n+m=$ number of samples $j=1,2,3, \ldots, 8$ (input index)

In this matrix, columns 1-8 are the input data and the last column indicates value of the cell obtained from the observed data of urban change. The value of 1 in the last column indicates that a non-urban cell changed to urban and 0 indicates no change to urban. RMSE values are generated for each cycle. Then, the RMSE values are plotted against the number of training cycles (epochs) to identify the best fitting model.

\section{Results \\ Models calibration}

The training data in this study area includes $25 \%(50,000$ cells) of all the data, which $36 \%$ of these training data $(18,000$ cells) were entered (ANFIS, ANN and LR) to train and estimate the bias and the rest $64 \%(32,000$ cells) were used as the data check. The training data $(50,000$ cells) were $25 \%$ of the 1987 image data which have been used for calibrating the models as training and checking for ANN and ANFIS models and calculating LR parameters. The training data have been chosen from all the image area in a random manner which guarantees there is no bias in the selection. Then, after the selection of the sample data, the models are calibrated.

In this research, the nets have been trained until reaching a stable situation. As it is presented in Fig. 7, the ANN error curve (RMSE) for training data starts around 1.1 and reached under 0.4 after 1500 epochs. The ANN error curve for checking data starts around 1.25 and after 1500 epochs reached around 0.9.

For the ANFIS, Gaussian membership function with 0.1 as the initial step size is used. The step size decreasing and increasing rates were selected equal to 0.9 and 


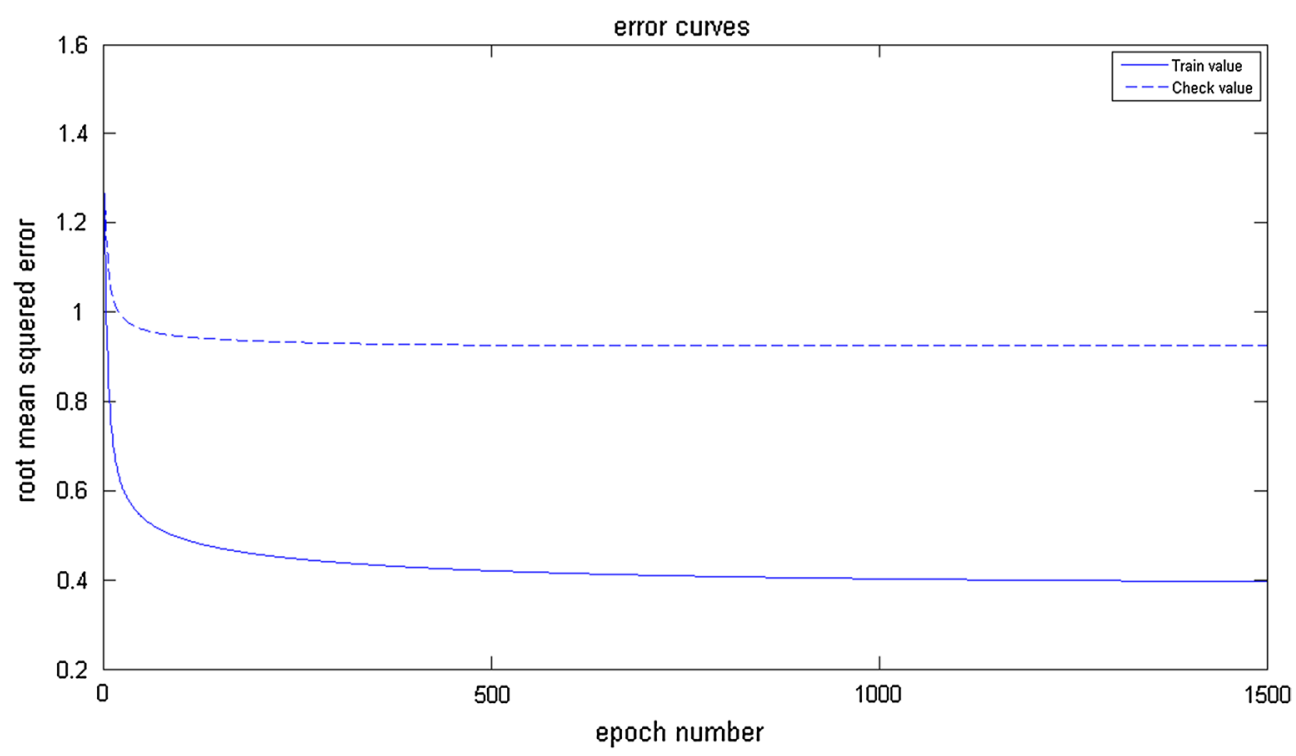

Fig. 7 ANN error curves

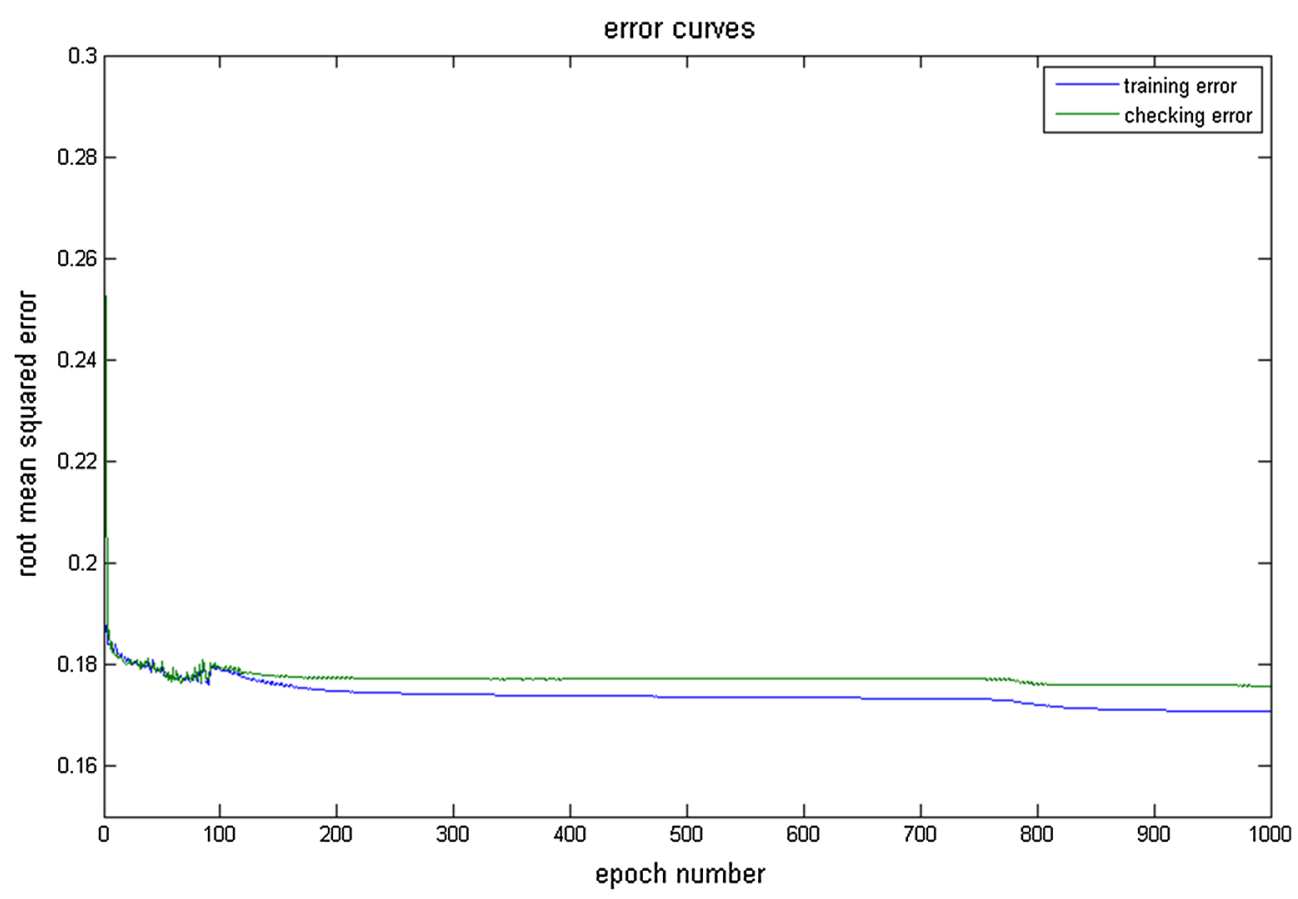

Fig. 8 ANFIS error curves

1.1, respectively. This method selects the number of membership functions from the input data. Figure 8 illustrates training run of ANFIS which RMSE was plotted across training cycles. The ANFIS error curve for training data and checking data starts around 0.19 and 0.25 , respectively. After 200 epochs, both of the curves missed their oscillation and have changed very smoothly toward their final values in epoch 1000 to around 0.17 for both of the training and checking data. The input and final membership functions are illustrated in Fig. 9.

The correlation between the input parameters is shown in Table 4. According to Table 4, correlation between neither of the pair input parameters have been more than 0.5 and this means the input parameters in this research have been independent. The LR calibrated results are 
a

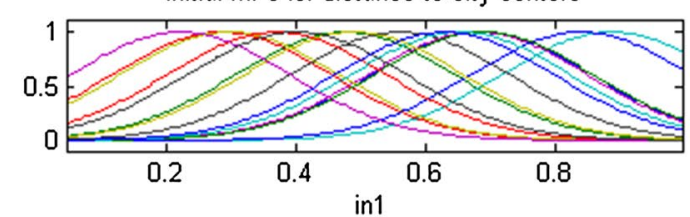

Initial MFs for distance to green spaces

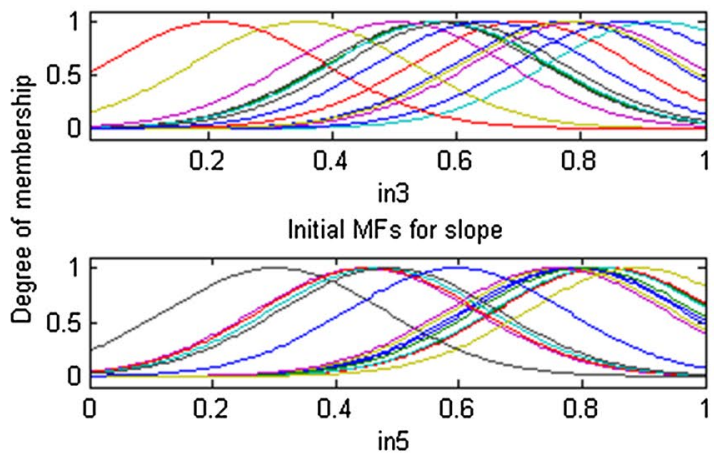

Initial MFs for distance to faults

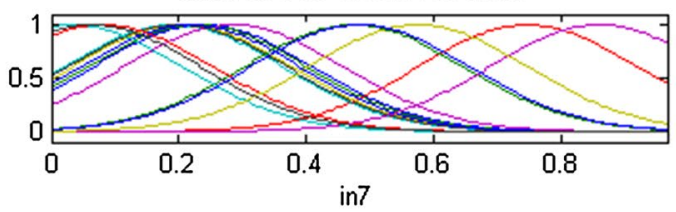

b

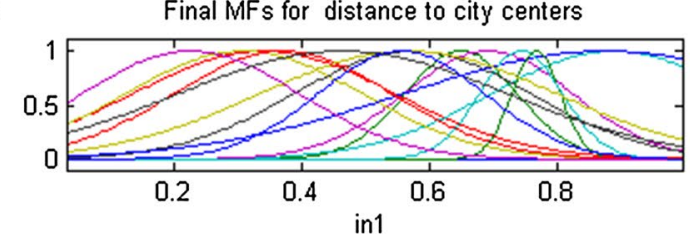

Final MFs for distance to green spaces

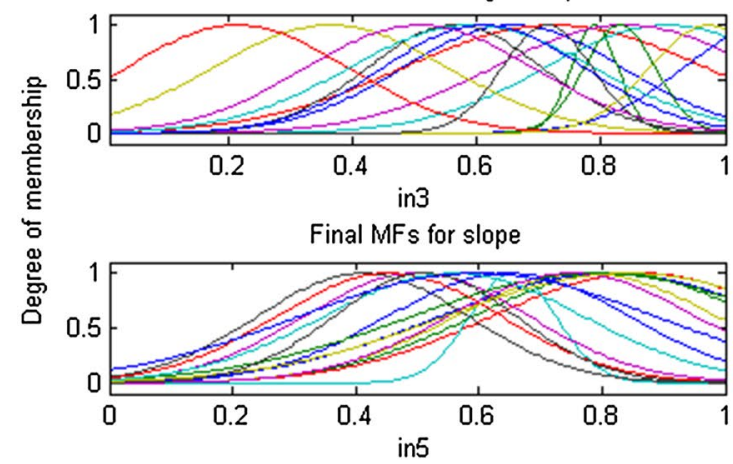

Final MFs for distance to faults

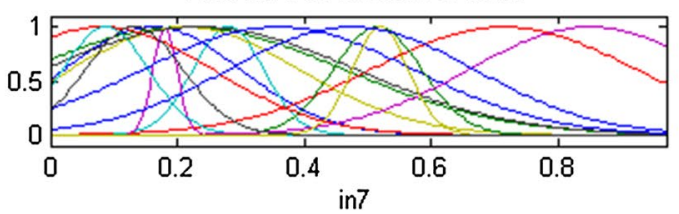

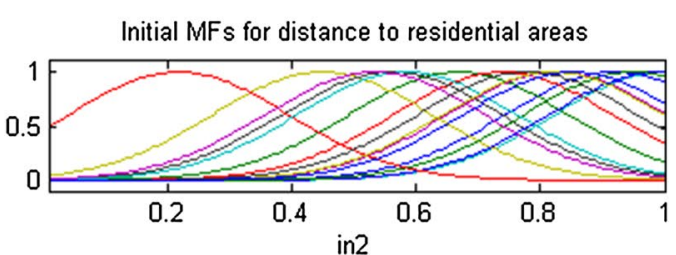

Initial MFs for elevation

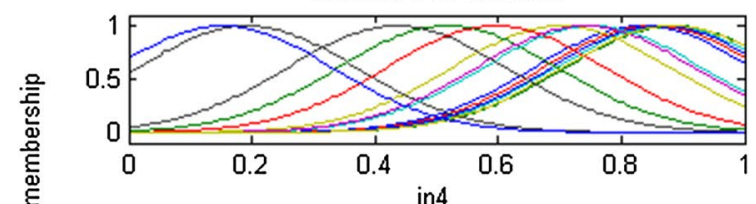

Initial MFs for distance to roads

哈

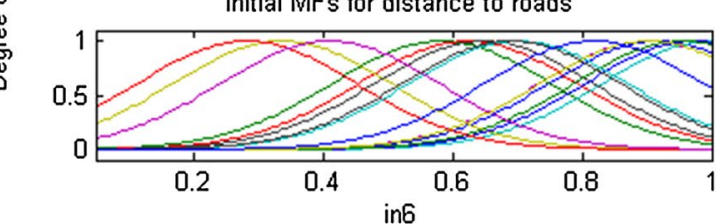

Initial MFs for number of urban cell in a $3 * 3$ neighborhood

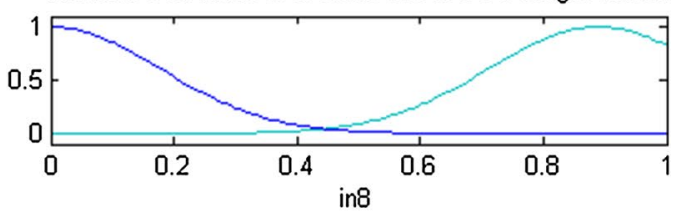

Final MFs for distance to residential areas

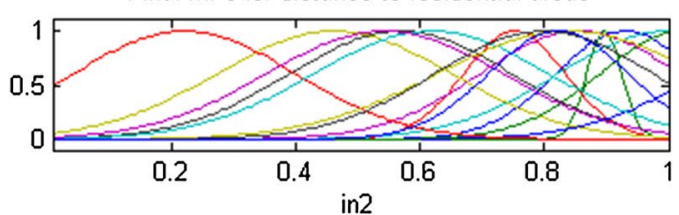

Final MFs for elevation

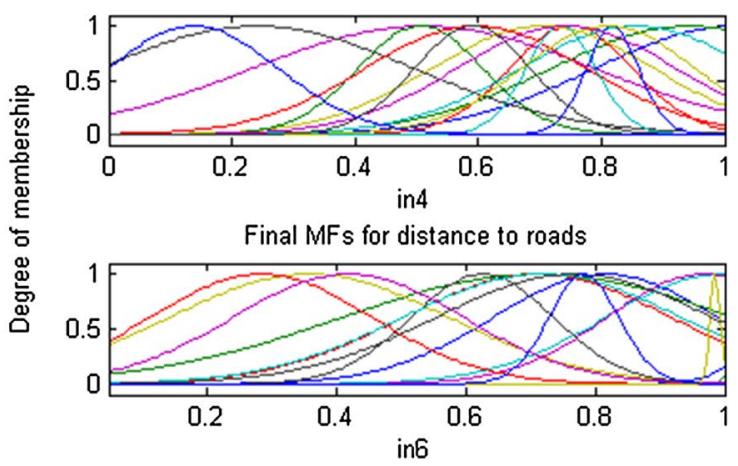

Final MFs for number of urban cell in a $3{ }^{\star 3}$ neighborhood

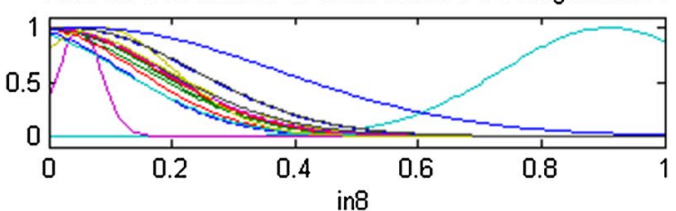

Fig. 9 a Initial membership functions. b Final (optimized) membership functions 
Table 4 LR correlation matrix

\begin{tabular}{|c|c|c|c|c|c|c|c|c|}
\hline Inputs variable & & & & & & & & \\
\hline Distance to region centers & 1 & 0.131 & -0.325 & -0.119 & 0.033 & -0.285 & 0.336 & -0.082 \\
\hline Distance to developed area & & 1 & -0.097 & 0.108 & -0.131 & -0.138 & -0.043 & -0.431 \\
\hline Distance to green space & & & 1 & -0.161 & -0.008 & -0.464 & -0.142 & 0.118 \\
\hline Elevation & & & & 1 & -0.255 & 0.084 & 0.315 & -0.009 \\
\hline Slope & & & & & 1 & 0.030 & 0.088 & -0.036 \\
\hline Distance to main road & & & & & & 1 & -0.158 & 0.011 \\
\hline Distance to fault & & & & & & & 1 & 0.055 \\
\hline Number of urban cell in a $3^{*} 3$ neighborhood & & & & & & & & 1 \\
\hline
\end{tabular}

shown in Table 5. According to Table 5, the distance to the developed areas and the distance to main roads are the most important drivers in growth of this city during 1987-2006. On the other hand, the slope and distance to the faults were the ones which had the least impact on Sanandaj urban growth.

\section{Accuracy assessment}

In this paper, Percent Area Match (PAM) metrics have been used to evaluate each model. PAM compares areas that are correctly predicted as change according to the model compared with areas that are converted to new areas in the observed map. PAM quantity [Eq. (4)] and location [Eq. (5)] are important for urban planners because it is vital for them to know the spatial location and quantity of land area within the urban boundary around the urban area. Values less than 1, indicates that the model underestimates the size of the urban area and values greater than 1 , reflects that the model overestimates urban area (Tayyebi et al. 2011).

$$
\begin{aligned}
& P A M \text { quantity }=\frac{A P t_{2}-A A t_{1}}{A A t_{2}-A A t_{1}} \\
& P A M \text { location }=\frac{\left(A P t_{2}-A A t_{1}\right)-\alpha}{A A t_{2}-A A t_{1}} \\
& \alpha=\frac{A P t_{2}-A A t_{2}}{A A t_{2}}
\end{aligned}
$$

where, $A A t_{1}$ is the area within actual urban boundary in time $1, A A t_{2}$ is the area within actual urban boundary in time $2, A P t_{2}$ is the area within predicted urban boundary in time 2.

Table 6 show the goodness of fit resulted from the training and checking data for all the three models. In

\begin{tabular}{|c|c|c|c|}
\hline Input variable & Coefficient & Standard error & Exp. (coefficient) \\
\hline Distance to region centers & 6.347 & 0.416 & 570.687 \\
\hline Distance to developed area & 19.496 & 0.973 & $2.932 \mathrm{E} 8$ \\
\hline Distance to green space & -0.759 & 0.450 & 0.468 \\
\hline Elevation & 1.196 & 0.206 & 3.305 \\
\hline Slope & -0.029 & 0.170 & 0.972 \\
\hline Distance to main road & 10.013 & 0.959 & $2.232 \mathrm{E} 4$ \\
\hline Distance to fault & -0.315 & 0.244 & 0.730 \\
\hline Number of urban cell in a $3^{*} 3$ neighborhood & 3.429 & 0.121 & 30.848 \\
\hline Constant & -34.935 & 1.100 & 0.000 \\
\hline
\end{tabular}
this step, the best solution which has the best goodness

Table 5 LR parameters

Table 6 Simulation results for $\mathbf{2 0 0 0}$ map with training and check data using ANFIS, ANN and LR

\begin{tabular}{lllllll}
\hline Method & Area in $\mathbf{1 9 8 7} \mathbf{( \mathbf { k m } ^ { \mathbf { 2 } } )}$ & Area in $\mathbf{2 0 0 0} \mathbf{( \mathbf { k m } ^ { \mathbf { 2 } } )}$ & Predicted area in $\mathbf{2 0 0 0} \mathbf{( \mathbf { k m }} \mathbf{2}$ & PAM quantity & PAM location & Situation \\
\hline ANFIS & 2.9720 & 4.8580 & 4.8848 & 1.0142 & 1.0113 & Overestimate \\
ANN & 2.9720 & 4.8580 & 4.8995 & 1.022 & 1.0174 & Overestimate \\
LR & 2.9720 & 4.8580 & 4.9182 & 1.0319 & 1.0253 & Overestimate \\
\hline
\end{tabular}



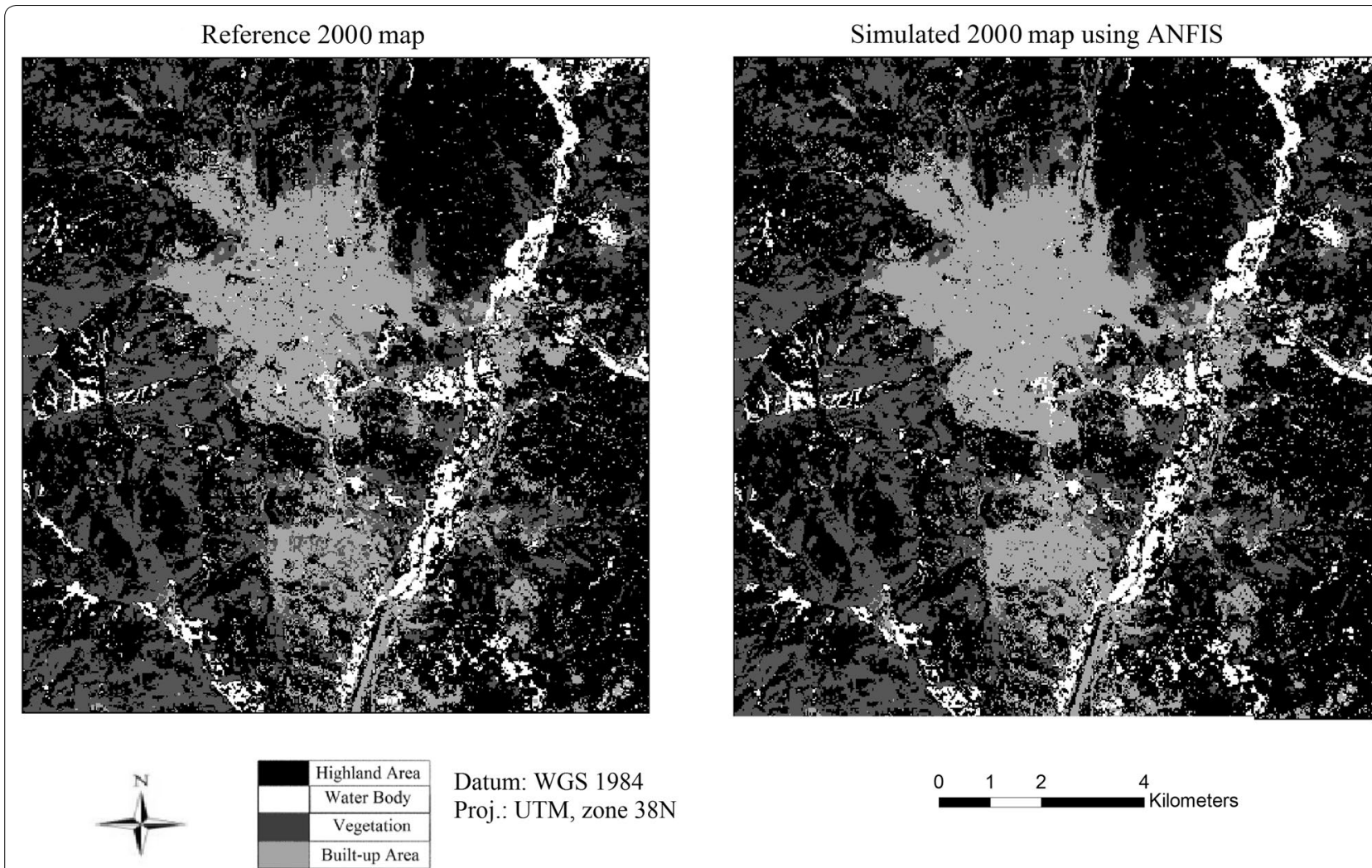

Fig. 10 Reference Sanandaj 2000 map and its simulated 2000 map using ANFIS

of fit is selected as a final method for modeling urban growth of the 2000 and 2006 maps. According to Table 6, the ANFIS model has had the best goodness of fit among the three models. Thus, this model is used for modeling urban growth in 1987-2000 and 2000-2006. Figures 10 and 11 show the results of the Sanandaj growth simulation for 2000 and 2006 respectively using ANFIS model (the best model). Tables 7 and 8, show the results of implementing the ANFIS model for modeling urban growth for 2000 and 2006.

\section{Discussion}

In Sanandaj city during the 1987-2006, the most significant growth has occurred in the southern part of the city. Although, in the north, east and west of city, urban growth has been occurred. However, exiting of the high elevation areas in the west, southwest, north and northeast played as a burrier role in the development of these regions. In addition, the areas in the south west have experienced more growth, as these areas are well served by the urban road network and had appropriate elevation and slope situation.
According to Table 5, distance to developed areas and distance to main roads due to their high values have been the most important factors in the expansion of Sanandaj city during 1987-2006. On the other side, slope and distance to fault had the least impact in expansion of the city due to their small values.

According to Table 6, the ANFIS model has the best goodness of fit among the three models. The predicted urban areas for 2000 map using training and checking data in ANFIS method has been so close to the real urban area for 2000 map than ANN and LR results. Also, the predicted urban area using ANFIS model for 2000 and 2006 maps (Tables 7, 8) have created PAM location and quantity values close to 1 which means the predicted area in both 2000 and 2006 maps have had acceptable agreement with the real ones.

As observed from the existing growth trends until 2006, urban growth policies have not paid serious attention to risk assessments factor such as distance to faults in development of the city which can be a major challenge at high dense urban areas. 


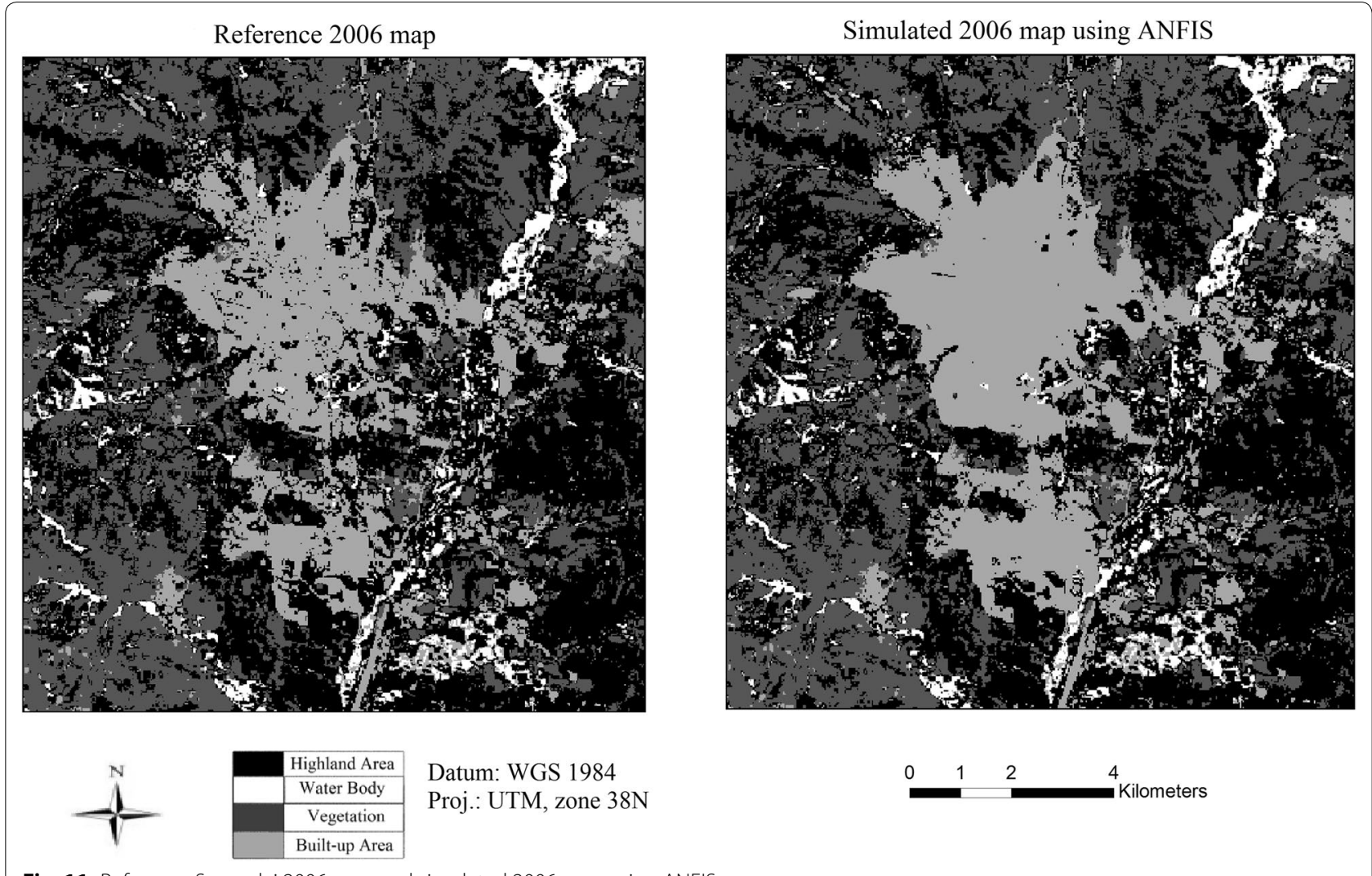

Fig. 11 Reference Sanandaj 2006 map and simulated 2006 map using ANFIS

Table 7 Simulation results for $\mathbf{2 0 0 0}$ map (testing data) using ANFIS

\begin{tabular}{lllllll}
\hline Method & Area in $\mathbf{1 9 8 7}\left(\mathbf{k m}^{\mathbf{2}}\right)$ & Area in $\left.\mathbf{2 0 0 0} \mathbf{( k m}^{\mathbf{2}}\right)$ & Predicted area in $\mathbf{2 0 0 0} \mathbf{( k m}^{\mathbf{2})}$ & PAM quantity & PAM location & Situation \\
\hline ANFIS & 9.2076 & 15.1963 & 15.2436 & 1.0079 & 1.0073 & Overestimate \\
\hline
\end{tabular}

Table 8 Simulation results for 2006 map using ANFIS

\begin{tabular}{lllllll}
\hline Method & Area in $\mathbf{2 0 0 0}\left(\mathbf{k m}^{\mathbf{2}}\right)$ & Area in $\left.\mathbf{2 0 0 6} \mathbf{( k m}^{\mathbf{2}}\right)$ & Predicted area in $\mathbf{2 0 0 6} \mathbf{( k m}^{\mathbf{2})}$ & PAM quantity & PAM location & Situation \\
\hline ANFIS & 17.7647 & 22.4977 & 22.6387 & 1.0298 & 1.0288 & Overestimate \\
\hline
\end{tabular}

Linguistic knowledge through fuzzy inference system can easily be used to model the urban development. So, knowledge and uncertainty about urban development can be easily incorporated into the modeling process. Needless to say that urban planners and urban managers need to provide rules or knowledge instead of exact mathematic expressions for spatial phenomena (AlKheder et al. 2008).

The results of research using ANFIS approach have had better goodness of fit than those of ANN and LR approaches in modeling urban growth for Sanandaj city.

\section{Conclusion}

Recently, in Iran, policy makers and urban planners and managers have begun to use urban growth models, both locally and nationally and policies related to land use and urban growth to support efficient use of land and natural resources (Tayyebi et al. 2011). So, urban growth models are powerful tools for urban planners and decision 
makers to manage and analyse directions and volumes of expansion of cities.

Combination of remote sensing data, geospatial information systems and artificial intelligence can be a powerful and useful method to analyse and model environmental phenomena such as urban growth. This combination has the potential to support such models by providing data and analytical tools for the study of urban planning. In fact, GIS and RS are considered as new reliable ways providing the necessary information and intelligence for planning proposals and can be used as monitoring tools during the implementation of plans.

The result of using more membership functions in ANFIS algorithm is that more accuracy can be achieved in the fewer epochs. On the other hand, use of more membership functions means that the network architecture needs more memory and also more time to reach the predefined error threshold value.

Neither of the considered methods, has limitation on the input data, evaluation and sensitive analysis consideration. They support all kind of input data such as socioeconomic and biophysical data. In a number of commonly used methods such as SLEUTH, the method cannot support socioeconomic data such as population. In addition, in the software based methods like SLEUTH, there is no way for considering sensitive analysis. Increasing the number of input parameters in ANFIS structure could be done with the least change in structure and program. Like other method with an ANN component, in ANFIS the weights and bias of each neuron could not be elaborate separately. This issue is one of the most important ANN's drawbacks. Thus, in this aspect LR model is simple, clear and has an interpretable structure that could easily determine the weights and importance of each input.

In this study, ANFIS model had the benefits of using neural networks and fuzzy logic at the same time. It was able to identify important factors in the development and their relationship and influence on the growth of the city.

Uncertainty is an indispensable component of spatial phenomena. Urban expansion due to its spatio-temporal nature has greatly affected by uncertainty. ANFIS includes fuzzy inference which is able to deal with uncertainty.

Due to LR model's simplicity and fast processing capability, it is a well-known method in urban growth and land use change modeling. However, it should be mentioned that this method in unable to model the nonlinear parts of the land use change phenomenon and the huge difference between the result of LR and ANFIS may be due to their structures. On the other hand, ANFIS is a well-known method in nonlinear problems, therefore; it has this ability to deal with complex problems such as urban growth.

Dealing with large data set is a traditional issue in environmental modeling like urban growth and land use change modeling. One of the solutions for the future researches could be clustering the input data and selecting the important ones to make the processing time shorter.

Using satellite imageries with high spatial resolution such as IKONOS, Quickbird and Orbveiw may enhance the classification accuracies. In this study, three Landsat imageries acquired at 1987, 2000 and 2006 have been used. But it should be mentioned that for a developing country like Iran which historical urban data and land use map is not stored properly or even existed, this research using free and reliable satellite imageries data which is the single source of data for these regions is a practical and scientific method for analyzing urban growth.

Received: 30 April 2016 Accepted: 28 July 2016

Published online: 04 August 2016

\section{References}

Al-Kheder S, Wanga J, Shana J (2008) Fuzzy inference guided cellular automata urban-growth modelling using multi-temporal satellite images. Int J Geogr Inf Sci 22(11-12):1271-1293

Almeida CM, Glerian JM, Castejon EF, Soares- Filhob BS (2008) Using neural networks and cellular automata for modeling intra-urban land-use dynamics. Int J Geogr Inf Sci 22(8-9):943-963

Anderson JR, Hardy EE, Roach JT, Witmer RE (1976) A land use and land cover classification system for use with remote sensor data. US Geol Surv Prof Pap 964:28

Armstrong J, Fildes R (2006) Making progress in forecasting. Int J Forecast 22:433-444

Asselt MV, der Molen FV, Faas N, Veenman S (2010) Uit zicht: toekomstverkennen met beleid. Wetenschappelijke Raad voor het Regeringsbeleid, Den Haag

Batty M, Howes D (2001) Predicting temporal patterns in urban development from remote imagery. In: Donnay JP, Barnsley MJ, Longley PA (eds) Remote Sensing and urban analysis. Taylor and Francis, London, pp 185-204

Berrogi G (1997) Decision modeling in policy management. Technol Forecast Soc Chang 72(2):161-173

Chiu S (1994) Fuzzy model identification based on cluster estimation. J Intell Fuzzy Syst 2(3):267-278

Christensen R (1997) Log-linear models and logistic regression, 3rd edn. Springer-Verlag, New York

Clarke KC, Parks BO, Crane MP (2002) Geographic information systems and environmental modeling. Prentice Hall, New Jersey

Cuhls K (2000) Opening up foresight processes participation and networking. In: E'conomies et Socie'te's. Cahiers de L'Ismea, Paris

Cuhls K (2003) From forecasting to foresight processes - new participative foresight activities in Germany. J Forecast 22:93-111

Dadras M, Shafri HZM, Ahmad N, Pradhan B, Safarpour S (2015) Spatio-temporal analysis of urban growth from remote sensing data in Bandar Abbas city, Iran. Egypt J Remote Sens Space Sci 18:35-52

Deep S, Saklani A (2014) Urban sprawl modeling using cellular automata. Egypt J Remote Sens Space Sci 17:179-187 
Dickerson JA, Kosko B (1996) Fuzzy function approximation with ellipsoidal rules. IEEE Trans Syst Man Cybern Part B Cybern 26(4):542-560

Donnay JP, Barnsley MJ, Longle PA (2001) Remote sensing and urban analysis. In: Donnay JP, Barnsley MJ, Longley PA (eds) Remote sensing and urban analysis. Taylor and Francis, London, pp 3-18

Enserink B, Hermans L, Kwakkel J, Thissen W, Koppenjan J, Bots P (2010) Policy analysis of multi-actor systems. Lemma, Den Haag

Foroutan E, Delavar MR, Araabi BN (2012) Integration of genetic algorithms and fuzzy logic for urban growth modelling. ISPRS Ann Photogramm Remote Sens Spat Inf Sci 1:69-74

Goodchild MF (2000) Spatial analysis: methods and problems in land use management. In: Hill MJ, Aspinall RJ (eds) Spatial information for land use management. Gordon and Breach Science Publishers, Singapore, pp 39-50

Goodwin P, Wright G (2010) limits of forecasting methods in anticipating rare events. Technol Forecast Soc Chang 77:355-368

Guan Q, Wang L (2005) An artificial-neural-network-based constrained CA model for simulating urban growth and its application. In: Auto-curto conference, 18-23 March 2005, Las Vegas, NV. http://www.geog.ucsb. edu1-guanlpapedGuan-AutoCarto2005.pdf. Accessed 26 Dec 2005

Herold M, Menz G, Clarke KC (2001) Remote sensing and urban growth model demands and perspectives. symposium on remote sensing of urban areas, Regensburger Geographische Schriften, Regensburg, Germany, June 2001, vol. 35, on supplement CD- ROM

Herold M, Goldstein N, Clarke K (2003) The spatio-temporal form of urban growth: measurement, analysis and modeling. Remote Sens Environ 85:95-105

Huang S, Huang Y (1991) Bounds on the number of hidden neurons in multilayer perceptrons. IEEE Trans Neural Networks 2(1):47-55

Huang SH, Xing H (2002) Extract intelligible and concise fuzzy rules from neural networks. Fuzzy Sets Syst 132(2):233-243

Im J, Jensen J, Tullis J (2008) Object-based change detection using correlation image analysis and image segmentation. Int J Remote Sens 29:399-423

IPTS-JRC (2008) On-line foresight guide. JRC-IPTS, Sevilla

Jang JR (1993) ANFIS: adaptive-network-based fuzzy inference system. IEEE Trans Syst Man Cybern 23(3):665-685

Jensen JR, Cowen DC (1999) Remote sensing of urban/suburban infrastructure and socio-economic attributes. Photogramm Eng Remote Sens 65(5):611-622

Koomen E, Diogo V, Dekkers J, Rietveld P (2015) A utility-based suitability framework for integrated local-scale land-use modelling. Comput Environ Urban Syst 50:1-14

Kumar DS, Arya DS, Vojinovic Z (2013) Modeling of urban growth dynamics and its impact on surface runoff characteristics. Comput Environ Urban Syst 41:124-135

Li X, Yeh AGO (2001) Calibration of cellular automata by using neural networks for the simulation of complex urban systems. Environ Plan A 33:1445-1462

Li X, Yeh AGO (2002) Urban simulation using principal components analysis and cellular automata for land-use planning. Photogramm Eng Remote Sens 68(4):341-352

Li X, Yeh AGO (2004) Analyzing spatial restructuring of land use patterns in a fast growing region using remote sensing and GIS. Landsc Urban Plan 69:335-354

Li L, Sato Y, Zhu H (2003) Simulating spatial urban expansion based on a physical process. Landsc Urban Plan 64:67-76

Meiyappan P, Dalton M, O'Neill C, Atul B, Jain AK (2014) Spatial modeling of agricultural land use change at global scale. Ecol Model 291:152-174

Mitaim S, Kosko B (2011) The shape of fuzzy sets in adaptive function approximation. IEEE Trans Fuzzy Syst 9(4):637-656

Mohammady S, Delavar MR, Pijanowski BC (2013) Urban growth modeling using ANFIS algorithm: a case study for Sanandaj city, Iran. Int Arch Photogramm Remote Sens Spatial Inf Sci 3:493-498. doi:10.5194/ isprsarchives-XL-1-W3-493-2013
Montello DR, Freundschuh SM (2005) Cognition of geographic information. In: McMaster RB, Usery EL (eds) A research agenda for geographic information science. CRC Press, Boca Raton, pp 61-91

Morris J, Porter D, Neet M, Noble PA, Schmidt L, Lapine LA, Jensen JR (2005) Salt and brackish marsh characterization at North Inlet, SC using LIDARderived elevation data and land cover extracted from multispectral imagery using a neural network. Int J Remote Sens 26:5221-5234

Nowotny H (2008) Insatiable curiosity: innovation in a fragile future. Cambridge Mamit Press, Cambridge

Overmars KP, Verburg PH, Veldkamp T (2007) Comparison of a deductive and an inductive approach to specify land suitability in a spatially explicit land use model. Land Use Policy 24(3):584-599

Pahlavani P, Delavar MR (2014) Multi-criteria route planning based on a driver's preferences in multi-criteria route selection. Transp Res Part C 40:14-35

Panagoulia D (2006) Artificial neural networks and high and low flows in various climate regimes. Hydrol Sci J 51(4):563-587

Pijanowski BC, Shellito B, Pithadia S (2002) Using artificial neural networks, geographic information systems and remote sensing to model urban sprawl in coastal watersheds along eastern Lake Michigan. Lakes Reserv 7:271-285

Pijanowski BC, Pithadia S, Shellito BA, Alexandridis K (2005) Calibrating a neural network-based urban change model for two metropolitan areas of Upper Midwest of the United States. Int J Geogr Inf Sci 19:197-215

Pijanowski BC, Tayyebi A, Delavar MR, Yazdanpanah MJ (2009) Urban expansion simulation using geographic information systems and artificial neural networks. Int J Environ Res 3(4):493-502

Pijanowski BC, Tayyebi A, Doucette J, Pekin BK, Braun D, Plourde J (2014) A big data urban growth simulation at a national scale: configuring the GIS and neural network based land transformation model to run in a high performance computing (HPC) environment. Environ Model Softw 51:250-268

Rumelhart DE, McClelland JL (eds) (1986) Parallel distributed processing: explorations in the microstructure of cognition, vol. 1: foundations. The MIT Press, Cambridge

Schwartz P (1991) The Art of the long view: planning for the future in an uncertain world. Doubleday, New York

Sousa S, Caeiro S, Painho M (2002) Assessment of map similarity of categorical maps using kappa statistics: the case of sado estuary. Paper presented at the ESIG 2002, Tagus Park, Oeiras

Tayyebi A, Pijanowski BC, Tayyebi AH (2011) An urban growth boundary model using neural networks, GIS and radial parameterization: an application to Tehran, Iran. Landsc Urban Plan 100:35-44

Triantakonstantis DP (2012) Urban growth modeling using determinism and stochasticity in a touristic village in western Greece. Open J Civil Eng 2:42-48

Triantakonstantis D, Mountrakis G (2012) Urban growth prediction: a review of computational models and human perceptions. J Geogr Inf Syst 4:555-587

Veenman SA (2013) Futures studies and uncertainty in public policy: a case study on the ageing population in the Netherlands. Futures 53:42-52

Veldkamp A, Lambin EF (2001) Predicting land-use change. Agric Ecosyst Environ 85:1-6

Wang F (1994) The use of artificial neural networks in a geographical information system for agricultural land-suitability assessment. Environ Plan A 26:265-284

Weng Y (2007) Spatiotemporal changes of landscape pattern in response to urbanization. Landsc Urban Plan 81:341-353

Yan Z (2010) Algorithms of extracting fuzzy rules from sample data. In: Intelligent computing and intelligent systems (ICIS). International conference, Shanghai, China, Oct 29-31, 2010, pp 823-827

Yeh AGO, Li X (2003) Simulation of development alternatives using neural networks, cellular automata and GIS for urban planning. Photogramm Eng Remote Sens 69(9):1043-1052 